\title{
GIS Application in Evaluating the Potential Habitat of Giant Pandas in Guanyinshan Nature Reserve, Shaanxi Province
}

\author{
P. F. Wu ${ }^{1}$, X. H. Liu $^{2, *}$, X. M. Shao ${ }^{1, *}$, Y. Zhu ${ }^{3}$, Q. $\mathrm{Cai}^{3}$ \\ ${ }^{1}$ College of Biological Science, Chinese Agricultural University, Beijing 100193, China \\ ${ }^{2}$ School of Environment, Tsinghua University, Beijing 100084, China \\ ${ }^{3}$ Guanyinshan Nature Reserve, Foping County, Shaanxi 723400, China
}

Received 7 January 2012; revised 25 January 2013; accepted 7 March 2013; published online 31 March 2013

\begin{abstract}
Guanyinshan Nature Reserve (GNR) is located in the middle of the Qinling Mountains in Shaanxi Province, which connects two local populations of giant pandas (Ailuropoda melanoleuc) which are Xinglongling population and Tianhuashan population. In this research, the suitability of potential habitat in GNR was analyzed and evaluated by using GIS technology in order to get a comprehensive grasp of the habitat quality spatially. Our results showed that (1) when not considering human activities, the "most suitable" potential habitat covers 6.03 ha occupying $0.04 \%$ of the total area mainly because of very sparse distribution of Bashania fargesii bamboo. The unsuitable potential habitat covers 1097.10 ha occupying $7.63 \%$ of the total area with very low bamboo coverage. The areas of "suitable" and "marginally suitable" habitat are 12767.94 ha and 506.70 ha, accounting for of 88.81 and $3.52 \%$ of the whole reserve respectively. (2) When considering the impact of residences and roads, the suitability degrades and the proportion of unsuitable area increases. In future, one way of protecting the habitat and the giant panda population is to reduce human activities as much as possible and the other is to implement proper scientific management and effective measures to promote regeneration and restoration of the habitat that has been impacted or destroyed.
\end{abstract}

Keywords: potential habitat, evaluation, GIS, giant pandas, suitability

\section{Introduction}

Habitat is the place where animals live. Generally, it is often determined by biotic and abiotic factors. In other words, habitat is the sum of every environmental factor and resource that is required for animal species. For example, factors such as elevation, slope, bamboo, etc., interact with each other and can lead to a strong influence on giant panda (Ailuropoda melanoleuc) survival. It is always a useful step to evaluate the habitat of giant pandas for the effective protection and management of its population (Zhou et al., 2006). Moreover, the way to evaluate the habitat of giant pandas is a key to the issue of how a population has previously been decreasing so rapidly and further explanations could also be acquired from the evaluation for knowing the habitat characteristic, fragmentation and isolation (Xiao et al., 2004).

The Qinling Mountains are the northern edge of the giant panda distribution and there has been much research on many aspects of habitat in Foping and Changqing Nature Reserves (FNR and CNR) on the southern slope of the Qinling Mountains. These studies include evaluation of habitat (Liu et al.,

${ }^{*}$ Corresponding author. Tel.: +86 $1062794119 / 62734691$; fax: +86 10 62794119/62734691.E-mail address: xuehua-hjx@tsinghua.edu.cn (X. H. Liu); shaoxm@ cau.edu.cn (X. M. Shao).

ISSN: 1726-2135 print/1684-8799 online

(C) 2013 ISEIS All rights reserved. doi:10.3808/jei.201300232
2004; Liu et at., 2006), selection and use of habitat (Pan et al., 1988, 2001; Yong et al., 2004; Liu et al., 2005) and analysis of patterns of giant panda activities (Zhang et al., 2004). Liu et al. (2008) studied the habitat selection of giant pandas and compared their differences in FNR and CNR and pointed out that giant pandas often make use of areas with elevation of 1200 $2600 \mathrm{~m}$, a moderate slope of $20 \sim 40^{\circ}$, and a mixed coniferbroadleaf forest with abundant bamboo understory.

As known, forest with preferred bamboo is the suitable habitat for giant pandas. Unfortunately, forest structure often suffers every kinds of influence from humans. The diversity of the forest communities, especially the structure of forest layers, has been strongly influenced by human activities (Zhou et al., 2006). Among human activities, timber cutting is one of the most common activities and can cause serious negative influence on the integrity of forest structure and then make the habitat degraded.

According to the local people, GNR was previously a suitable place for giant pandas to inhabit. Unfortunately, the giant pandas in GNR lost their habitat mainly due to intensive human activities such as commercial logging and extensive farming. Therefore, the animal was not spotted in the Second National Survey on Pandas in the period of $1985 \sim 1988$. Only a few panda traces were found in the Danangou valley next to FNR.

The Natural Forest Protection Programme started in 1999 

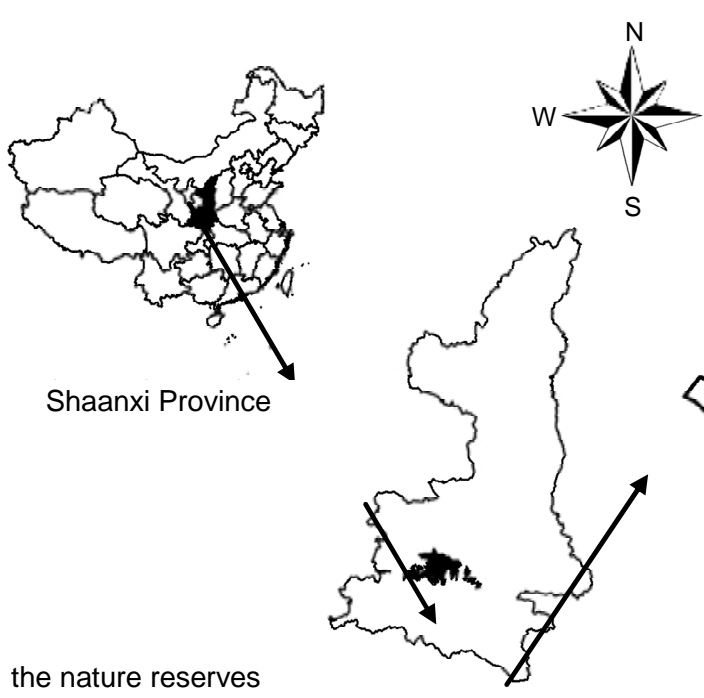

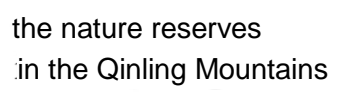
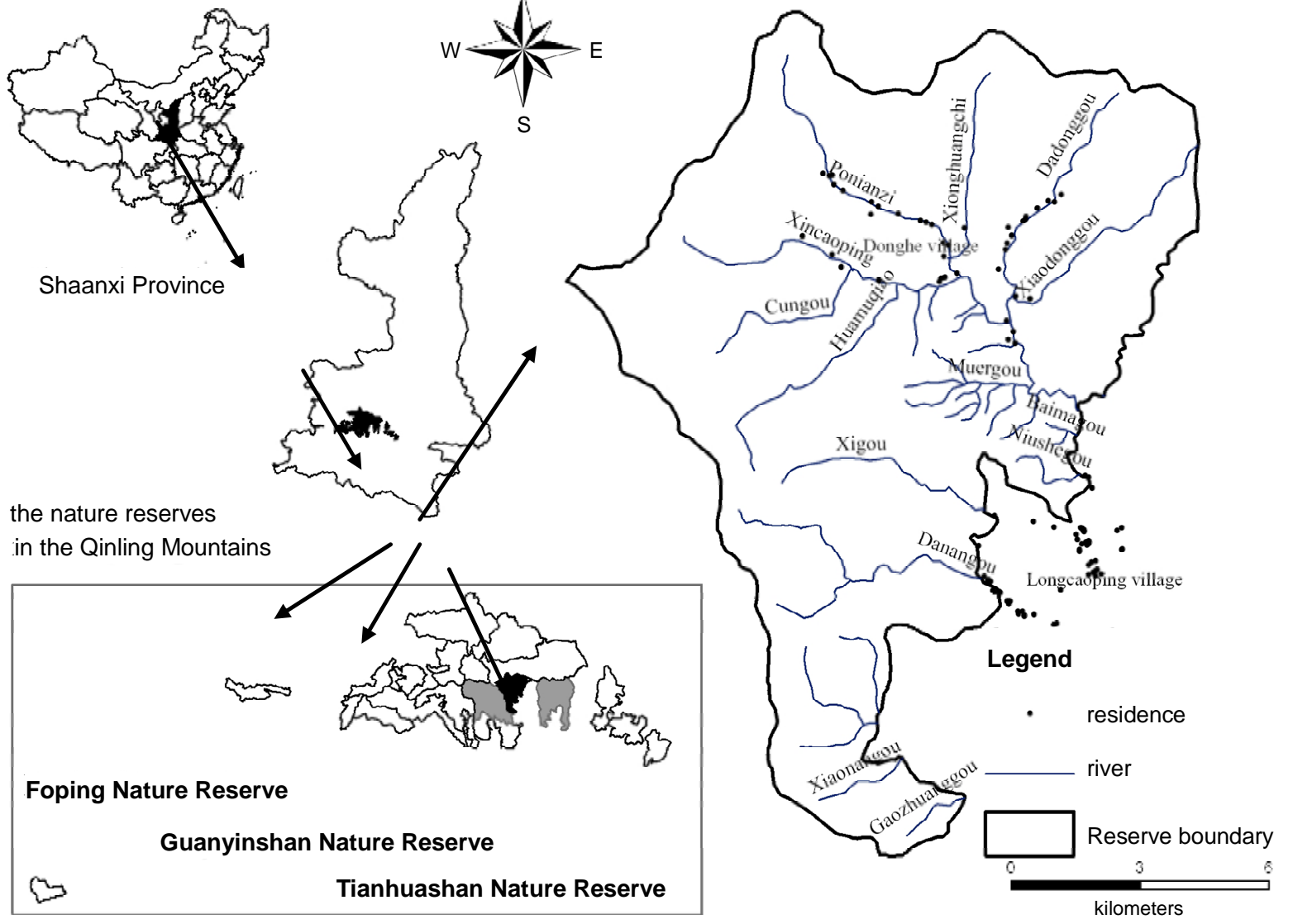

Figure 1. The location of Guanyinshan Nature Reserve in Shaanxi Province.

with the purpose of forbidding the exploitation of nature forests. In 2002 GNR was established with the aim of protecting the forest structure and habitat for the giant panda. All these measures have caused the regeneration and restoration of the forests. Consequently, the Third National Survey on giant panda and the habitat from 1999 to 2003 showed that many traces of giant panda activities were found in the adjoining areas of GNR and the neighboring FNR. However, for those areas strongly influenced by logging, restoration might need a long period of time.

GNR lies in the core part of the Qinling Mountains and conects two local panda populations which are Xinglongling population and Tianhuashan population. It has suffered strongly from logging. Yet, little is known about the habitat of this area. Only through habitat evaluation and analysis can we understand the habitat situation in GNR and take more effective and feasible measures to protect the forests and restore the panda habitat for the neighboring dense giant panda population in FNR to migrate to GNR. Therefore, it is very important to perform this evaluation.

\section{Research Area}

GNR was founded in 2002 and is located in the central portion of the Qinling Mountains $\left(107^{\circ} 51^{\prime} \sim 108^{\circ} 01^{\prime} \mathrm{E}, 33^{\circ}\right.$ $35^{\prime} \sim 33^{\circ} 45^{\prime} \mathrm{N}$ ) in the core of its nature reserve network (Figure 1). The average annual temperature is $11.5^{\circ} \mathrm{C}$ with lowest temperatures reaching $-14.3^{\circ} \mathrm{C}$ and highest temperatures reaching $36.4{ }^{\circ} \mathrm{C}$. The average annual rainfall is $922.8 \mathrm{~mm}$. GNR has four main soil types, which changes with elevation from 1150 to $2574 \mathrm{~m}$. The area is covered with three major forest types which are conifer forest, mixed conifer-broadleaf forest, and deciduous broadleaf forest and three kinds of bamboo which are Bashania fargesii, Fargesia spathacea and Fargesia dracocephala.

\section{Methods}

\subsection{Selection of Habitat Factor}

The evaluation of habitat is based on a series of steps (Ron and Jyrki, 2001) which are always different and vary with the purpose and data collection when applied into practice. (Liu et al., 1998; Xiao et al., 2004; Xu et al., 2006)

Liu et al. (1997) evaluated the habitat of Wolong Nature Reserve (WNR) by applying GIS method and taking three factors of elevation, slope and bamboo into account. On the basis of these three factors, the concept of the potential habitat for GNR was defined in this paper. The evaluation of the potential habitat in GNR was carried out using the selected factors (Table 1). Among many factors of habitat, elevation is cri- 
Table 1. The Factors Selected for Evaluation of the Potential Panda Habitat in Guanyinshan Nature Reserve in Shaanxi Province

\begin{tabular}{llll}
\hline Suitability (score) & Most suitable (4) & Suitable (3) & Marginally suitable (2) \\
\hline Elevation & $2100-2574 \mathrm{~m}$ & $1300-1900 \mathrm{~m}$ & $1900-2100 \mathrm{~m}$ \\
Slope & $0-15^{\circ}$ & $15-30^{\circ}$ & $30-45^{\circ}$ \\
Bamboo type & Bashania fargesii & Fargesia spathacea & Fargesia dracocephala \\
Bamboo coverage & $0.3-0.7$ & $0.7-1.0$ & -
\end{tabular}

* Bamboo coverage refers to the percentage of vertical shade of bamboo in shrub layer with a radius of 10 meters.

Table 2. Two-Dimensional Classification of the Potential Panda Habitat in Guanyinshan Nature Reserve in Shaanxi Province

\begin{tabular}{|c|c|c|c|c|c|c|c|c|c|c|c|}
\hline & \multicolumn{5}{|c|}{ Slope suitability } & & \multicolumn{5}{|c|}{ Elevation-Slope suitability } \\
\hline \multirow{6}{*}{$\begin{array}{l}\text { Elevation } \\
\text { suitability }\end{array}$} & Score & 4 & 3 & 2 & 1 & \multirow{5}{*}{$\begin{array}{l}\text { Bamboo } \\
\text { quality } \\
\text { suitability }\end{array}$} & Score & 4 & 3 & 2 & 1 \\
\hline & 4 & 4 & 3 & 2 & 1 & & 4 & 4 & 4 & 3 & 1 \\
\hline & 3 & 3 & 3 & 2 & 1 & & 3 & 3 & 3 & 3 & 1 \\
\hline & 2 & 2 & 2 & 2 & 1 & & 2 & 2 & 2 & 2 & 1 \\
\hline & 1 & 1 & 1 & 1 & 1 & & 1 & 1 & 1 & 1 & 1 \\
\hline & \multicolumn{6}{|c|}{ Elevation-Slope suitability } & \multicolumn{5}{|c|}{ Final potential habitat suitability } \\
\hline
\end{tabular}

$* 1,2,3$ and 4 refer to the score of potential habitat suitability: not suitable, marginally suitable, suitable and most suitable respectively.

Table 3. The Criteria of Impact Factors in Guanyinshan Nature Reserve in Shaanxi Province

\begin{tabular}{lllll}
\hline Human impact (score) & Strong impact (4) & Impact (3) & Weak impact (2) & No impact (1) \\
\hline Distance to residence & $<400 \mathrm{~m}$ & $400-800 \mathrm{~m}$ & $800-1200 \mathrm{~m}$ & $\geq 1200 \mathrm{~m}$ \\
Distance to 108 National Road & $<100 \mathrm{~m}$ & $100-300 \mathrm{~m}$ & $300-500 \mathrm{~m}$ & $\geq 500 \mathrm{~m}$ \\
Distance to main road to FNR & $<50 \mathrm{~m}$ & $50-100 \mathrm{~m}$ & $100-200 \mathrm{~m}$ & $\geq 200 \mathrm{~m}$ \\
\hline
\end{tabular}

Table 4. The Criteria of Suitability Score of Potential Habitat under Impact of Human Activities

\begin{tabular}{lllll}
\hline Suitability Impact & Most suitable (4) & Suitable (3) & Marginally suitable (2) & Not suitable (1) \\
\hline Strong impact (4) & 1 & 1 & 1 & 1 \\
Impact (3) & 3 & 2 & 1 & 1 \\
Weak impact (2) & 3 & 2 & 2 & 1 \\
No impact (1) & 4 & 3 & 2 & 1 \\
\hline
\end{tabular}

$* 1,2,3$ and 4 refer to the score of the potential habitat suitability under impact of human activities, not suitable, marginally suitable, suitable and most suitable respectively.

tical to environment shaping since it affects the forest structure and soil structure. Considering animal's energy maintenance, slope is also an important factor in habitat evaluation because a steep slope is not suitable for giant pandas to move. In addition, the distribution of bamboo is an essential factor for giant pandas to survive because it forms their food base. Therefore, elevation, slope, and bamboo were selected for the evaluation of giant panda potential habitat in GNR.

\subsection{Evaluation of Single Habitat Factor}

Using ARCVIEW, we created the digital slope layer from digital elevation model. Both elevation and slope were classified into most suitable, suitable, marginally suitable, and not suitable based on Table 1. We assigned them with scores of 4, 3, 2 and 1 for the following calculation; therefore the suitability of elevation $\left(\mathrm{S}_{\mathrm{e}}\right)$ and slope $\left(\mathrm{S}_{\mathrm{s}}\right)$ can be evaluated.

There is no exact map of bamboo distribution in GNR. So based on the 299 field bamboo points we interpolated them to create a bamboo distribution map and a bamboo coverage map. The evaluation of these two bamboo factors $\left(\mathrm{S}_{\mathrm{bt}}\right.$ and $\left.\mathrm{S}_{\mathrm{bc}}\right)$ was again achieved based on Table 1 . Suitability evaluation of bamboo quality $\left(\mathrm{S}_{\mathrm{b}}\right)$ was implemented by using formula (1) and was also reclassified and assigned with score of 1-4:

$S_{\mathrm{b}}=\sum\left\{S_{\mathrm{bt}}, S_{\mathrm{bc}}\right\}$

where $S_{b}$ refers to suitability evaluation of bamboo quality; $S_{b t}$, $\mathrm{S}_{\mathrm{bc}}$ refer to evaluation of bamboo type and bamboo coverage respectively. In the reclassification of $\mathrm{S}_{\mathrm{b}}$ with the scores of $2 \sim$ 8 , scores of $2 \sim 3,4,5 \sim 7$ and 8 represented not suitable, marginally suitable, suitable and most suitable respectively.

\subsection{Evaluation of the Potential Habitat of Giant Pandas}

The evaluation of the potential panda habitat $\left(\mathrm{S}_{\mathrm{p}}\right)$ in GNR was carried out based on evaluation of each single factor using Table 2.

\subsection{Analysis of Impact from Residences and Roads}

As we know, human activities can strongly influence the potential panda habitat. In this article we take the impact of 


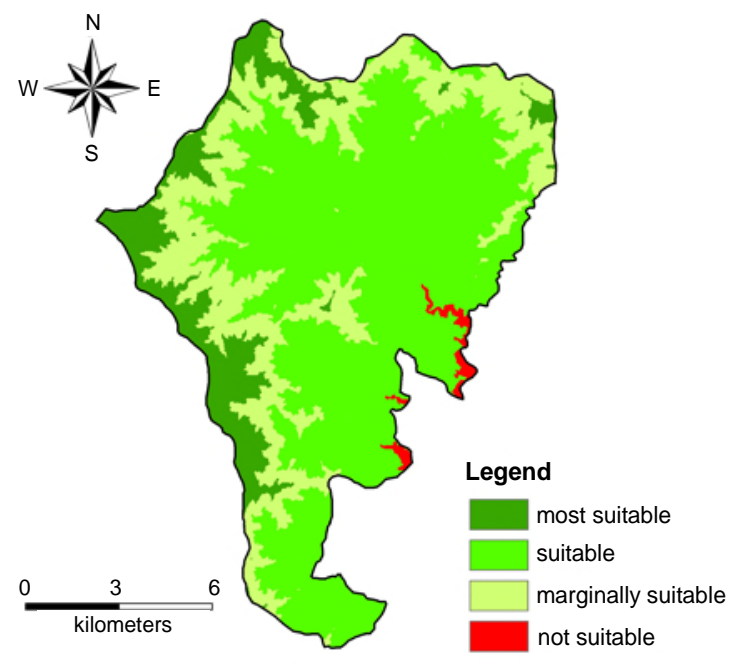

Figure 2. The evaluation of elevation suitability in Guanyinshan Nature Reserve in Shaanxi Province.

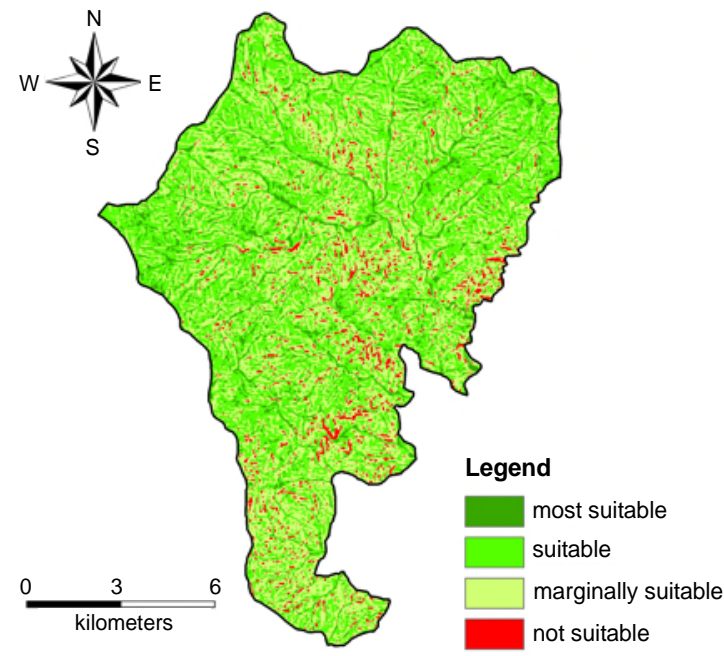

Figure 3. The evaluation of slope suitability in Guanyinshan Nature Reserve in Shaanxi Province.

Table 5. The Evaluation of Elevation Suitability in Guanyinshan Nature Reserve in Shaanxi Province

\begin{tabular}{llll}
\hline Suitability & $\begin{array}{l}\text { Class of elevation } \\
(\mathrm{m})\end{array}$ & Area (ha) & $\begin{array}{l}\text { Percent of } \\
\text { total area (\%) }\end{array}$ \\
\hline $\begin{array}{l}\text { Most suitable } \\
\text { Suitable }\end{array}$ & $\begin{array}{l}\text { 1100 }-2574 \\
\text { Marginally }\end{array}$ & 1751.22 & 12.18 \\
$\begin{array}{l}\text { suitable } \\
\text { Not suitable }\end{array}$ & $1900-21000$ & 8797.32 & 61.19 \\
\hline
\end{tabular}

residences and roads into account since they are the key human factors in GNR. We evaluated the impact of human activities based on Table 3, including impact of residences $\left(\mathrm{I}_{\mathrm{h}}\right)$ and impact of 108 National Road $\left(\mathrm{I}_{\mathrm{m}}\right)$ and impact of other roads $\left(I_{r}\right)$. With scoring of 1 to 4 shown in Table 3, the impact of human activities was evaluated using formula (2):

$I_{\mathrm{P}}={ }_{\operatorname{Max}}\left\{I_{\mathrm{h}}, I_{\mathrm{m}}, I_{\mathrm{r}}\right\}$
Table 6. The Evaluation of Slope Suitability in Guanyinshan Nature Reserve in Shaanxi Province

\begin{tabular}{llll}
\hline Suitability & Class of slope $\left(^{\circ}\right)$ & Area (ha) & $(\%)$ \\
\hline Most suitable & $0-15$ & 1210.05 & 8.42 \\
Suitable & $15-30$ & 6700.23 & 46.60 \\
Marginally suitable & $30-45$ & 5877.27 & 40.88 \\
Not suitable & $\geq 45$ & 590.22 & 4.10 \\
\hline
\end{tabular}

Table 7. The Evaluation of Bamboo Type in Guanyinshan Nature Reserve in Shaanxi Province

\begin{tabular}{llll}
\hline Suitability & Bamboo type & Area (ha) & $(\%)$ \\
\hline Most suitable & Bashania fargesii & 27.63 & 0.2 \\
Suitable & Fargesia spathacea & 12786.66 & 88.93 \\
Marginally suitable & Fargesia dracocephala & 1563.48 & 10.87 \\
Not suitable & no bamboo & 0 & 0 \\
\hline
\end{tabular}

Table 8. The Evaluation of Bamboo Coverage in Guanyinshan Nature Reserve in Shaanxi Province

\begin{tabular}{llll}
\hline Suitability & Bamboo coverage (\%) & Area (ha) & $(\%)$ \\
\hline Most suitable & $30-70$ & 12455.01 & 86.63 \\
Suitable & $\geq 70$ & 902.25 & 6.28 \\
Not suitable & $<30$ & 1020.51 & 7.09 \\
\hline
\end{tabular}

where $I_{P}$ refers to final impact of human activities on panda potential habitat; $I_{h}, I_{m}$ and $I_{r}$ refer to the impact of residences, 108 National Road and main road to FNR, respectively.

Based on the evaluation of impact of human activities $\left(\mathrm{I}_{\mathrm{P}}\right)$ and the evaluation of potential habitat $\left(\mathrm{S}_{\mathrm{p}}\right)$, the final evaluation results of the potential habitat were obtained using Table 4.

\section{Results}

\subsection{Results of Evaluating Three Single Factors}

Figure 2 and Table 5 showed the evaluation results of elevation suitability in GNR. Most of the GNR area is suitable for pandas to survive, and in total the ranked "most suitable" and "suitable" area account for $73.37 \%$ of the total area. The unsuitable area is only 151.02 ha, mainly lying at low altitude. The result of the slope evaluation (Figure 3 and Table 6) indicated that the "most suitable" area for panda survival is about $8.42 \%$ of the total area. Whereas the unsuitable area, which is not good for pandas to move with the slopes of $\geq 45^{\circ}$, occupies $4.10 \%$ of the total area.

Viewed from Figure 4a and Table 7, there are three types of bamboo in GNR: Bashania fargesii, Fargesia spathacea and Fargesia dracocephala. Bamboo Fargesia spathacea has a wide distribution around the area which covers $88.93 \%$ of the total area while Bashania fargesii is just found in few locations in the field survey. The amount of Fargesia dracocephala is between the other two types of bamboo mentioned above. The results of evaluation of bamboo coverage (Figure $4 \mathrm{~b}$ and Table 8) indicated the proportion of ranked "most suitable" is $86.63 \%$. The unsuitable area with bamboo coverage of $<30 \%$ is 1020.51 ha, accounting for $7.09 \%$ of the total area, 

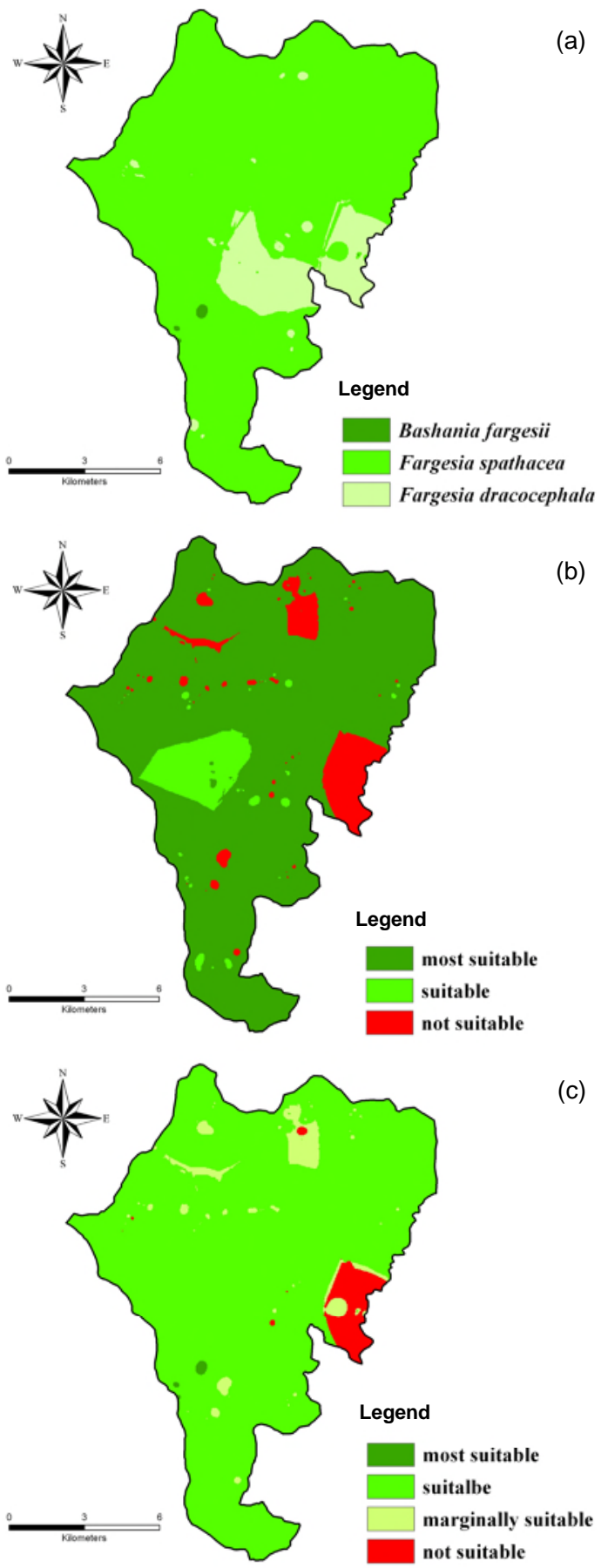

Figure 4. The evaluation of bamboo in Guanyinshan Nature Reserve in Shaanxi Province. a: bamboo distribution map; b: evaluation of bamboo coverage; c: evaluation of bamboo quality.

mainly lying at low altitude. Considering the bamboo type and bamboo coverage, the evaluation of bamboo quality (Figure $4 \mathrm{c})$ showed that the proportion of "most suitable" and "marginally suitable" area is 0.19 and $3.66 \%$ of the total area respectively. The former is the least due to little amount of Bashania fargesii, while the ranked "suitable" area is $92.72 \%$

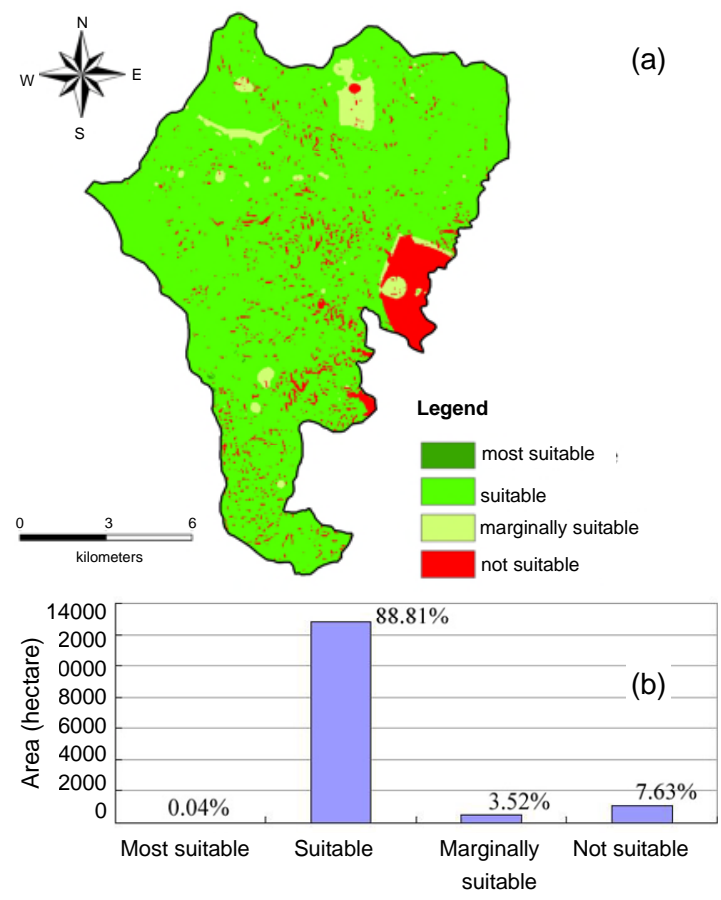

Figure 5. The evaluation of potential habitat in Guanyinshan Nature Reserve in Shaanxi Province. a: distribution map; b: statistics of classification.

of the total area for the major reason of wide distribution of Fargesia spathacea bamboo.

\subsection{Result of the Evaluation of Potential Habitat}

Figure 5 showed the evaluation of potential habitat in GNR based on the previous single factor evaluation. In total, the unsuitable area covers 1097.10 ha, taking a proportion of $7.63 \%$ of the total area mainly for low altitude distribution and low bamboo quality. The areas ranked "most suitable" and "marginally suitable" are 6.03 ha and 506.70 ha respectively, the former of which is also attributed to sparse distribution of Bashania fargesii bamboo. The area ranked "suitable" is 12767.94 ha with the proportion of $88.81 \%$ of the whole reserve because of high coverage of bamboo in the whole area.

\subsection{Impact of Residences and Roads on the Panda Habitat}

Figure 6 and Table 9 were the results of the evaluation of impact of residences and roads in GNR. Figure 6a showed that in this area the residences mainly concentrate in the Donghe and Longcaoping villages. Figure $6 \mathrm{~b}$ showed that there are two types of roads that might influence the course of panda migration, which are 108 National Road and the other roads to FNR and residences. Table 9 showed the various extents of impacts among three different human activities. The area of the residences with strong impact is 1189.80 ha, accounting for $8.28 \%$ of the total area. Donghe village is located inside the GNR and exerts strong influences on panda migration. The area with strong impact from the roads is 247.50 ha and 214.11 ha respectively. The evaluation of the total impact 


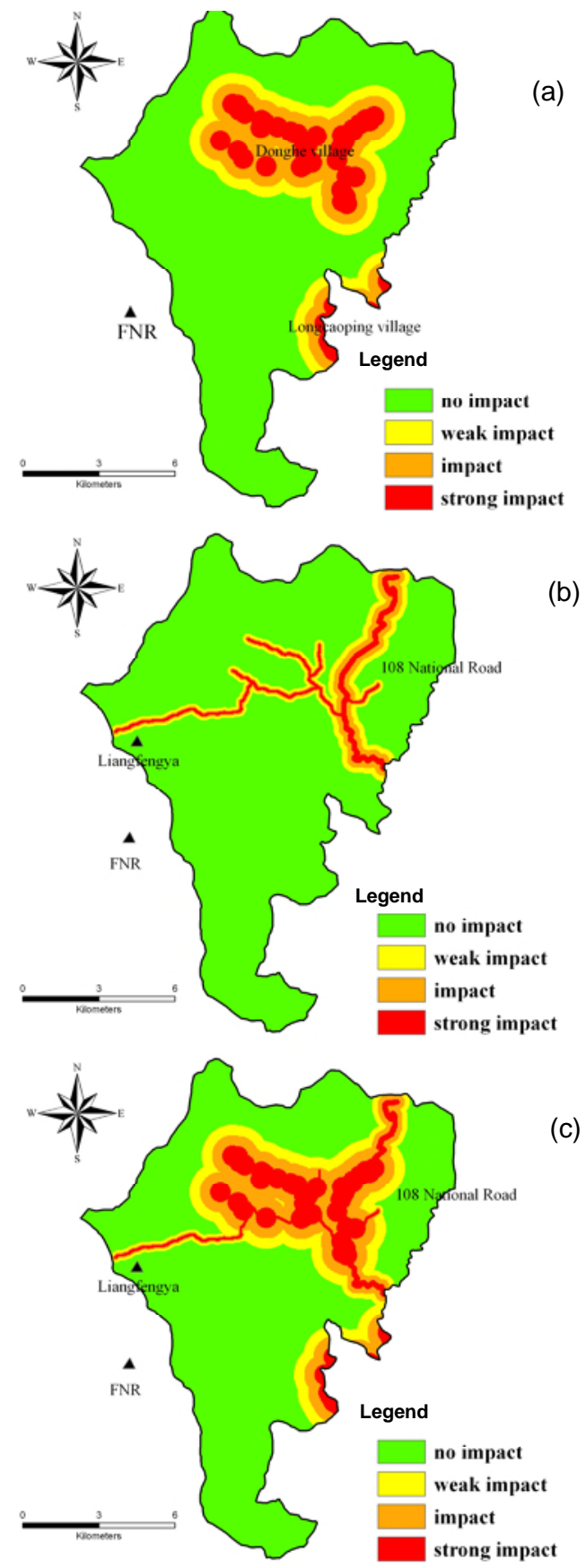

Figure 6. The impacts of human activities in Guanyinshan Nature Reserve in Shaanxi Province. a: impact of residences; b: impact of roads; c: final impact of residences and roads.

of the residences and roads was shown in Figure $6 \mathrm{c}$ which demonstrated that the area with strong impact is 1425.96 ha, accounting for $9.91 \%$ of the total area.

Figure 7 was the result of evaluating the potential habitat of giant pandas under impact of human activities of residences and roads. The unsuitable area is 2416.59 ha, accounting for $16.81 \%$ which is increased by $9.18 \%$ of the total area compared with the result of the evaluation of the potential habitat

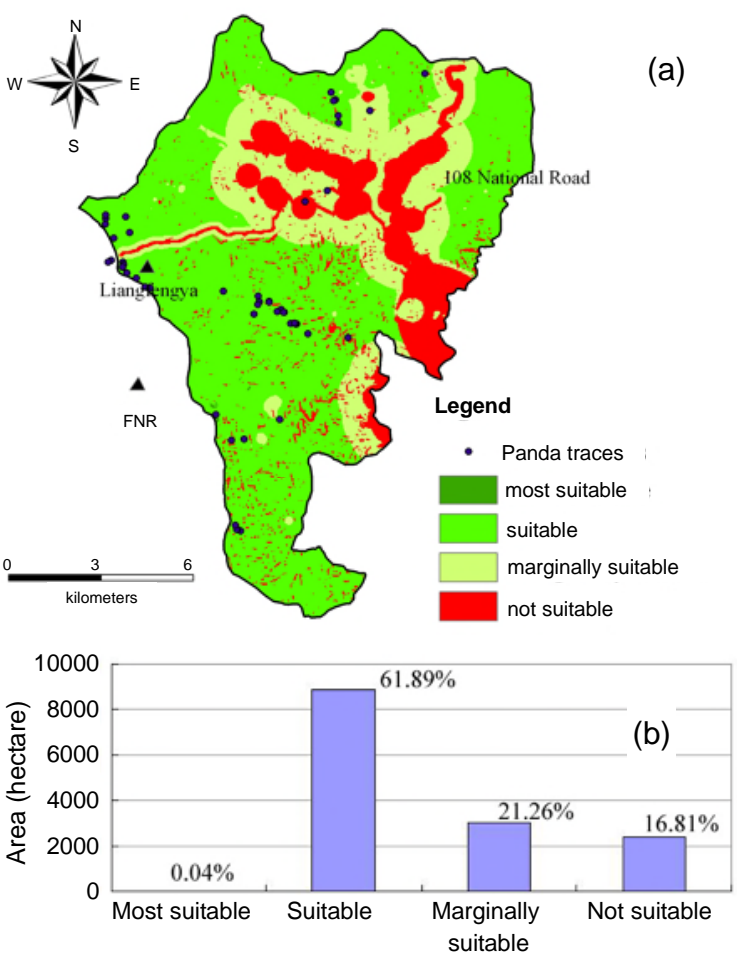

Figure 7. The evaluation of potential habitat under impact of residences and roads in Guanyinshan Nature Reserve in Shaanxi Province. a: distribution map overlaid with panda trace locations found in recent years; b: statistics of classification.

when the impact of human activities is not considered. With the human activities, the percentage of ranked "suitable" decreases from 88.81 to $61.89 \%$ of the total area while the proportion of ranked "marginally suitable" increases from 3.52 to $21.26 \%$.

\section{Discussion}

The loss and fragmentation of habitat lead directly to the loss of biodiversity which is vital for big animals especially for giant pandas. Only by understanding the quality of the habitat and the distribution can we take more effective measures to protect the giant pandas. Through our research, we know that there is a very wide range of bamboo distribution, which is good for panda survival. However, the giant panda distribution might be somewhat restricted by the lack of Bashania fargesii at low altitude of $1500 \sim 1900 \mathrm{~m}$ which is often selected by pandas as winter habitat in the neighbor FNR (Liu, 2001; Liu et al., 2008), which is known currently as one of the panda reserve with high density of wild panda population.

As for different areas, factors selected for habitat evaluation might be slightly different (Liu et al., 1999; Xiao et al., 2004). In this research the evaluation was completed using GIS. In evaluation of potential habitat, elevation, slope, and bamboo were considered, and in evaluation of human activeties, the impact of residences and roads were taken into account. 
Table 9. The Evaluation of Impact of Residences and Roads in Guanyinshan Nature Reserve in Shaanxi Province

\begin{tabular}{|c|c|c|c|c|}
\hline Class of impact & Strong impact (4) & Impact (3) & Weak impact (2) & No impact (1) \\
\hline $\begin{array}{l}\text { Impact of residence area (ha) / Percent of } \\
\text { total area }(\%)\end{array}$ & $1189.80 / 8.28$ & $1507.95 / 10.49$ & $1304.64 / 9.07$ & $10375.38 / 72.16$ \\
\hline $\begin{array}{l}\text { Impact of } 108 \text { National Road area (ha) / } \\
\text { Percent of total area (\%) }\end{array}$ & $247.50 / 1.72$ & $417.42 / 2.90$ & $416.07 / 2.89$ & $13296.78 / 92.49$ \\
\hline $\begin{array}{l}\text { Impact of other roads area (ha) / Percent of } \\
\text { total area (\%) }\end{array}$ & $214.11 / 1.49$ & $208.62 / 1.45$ & $369.63 / 2.57$ & $13585.41 / 94.49$ \\
\hline $\begin{array}{l}\text { Total impact of residences and roads } \\
\text { area (ha) / Percent of total area (\%) }\end{array}$ & $1425.96 / 9.91$ & $1707.39 / 11.88$ & $1462.05 / 10.17$ & 9782.37 / 68.04 \\
\hline
\end{tabular}

However, in evaluation of WNR by OuYang et al. (2001), vegetation was also regarded as one key factor besides elevation, slope, and bamboo. The elevation range of WNR is from 1500 to $6600 \mathrm{~m}$ and there is no distribution of forest and bamboo above the altitude of $3700 \mathrm{~m}$ where is so rarely used by giant pandas. Chen et al. (2005) indicated that pandas can be adaptive to a very wide range of forest structure when floristic composition and diversity were researched in Xiaozhaizigou Nature Reserve in Sichuan Province, and pointed out that broad-leaf forest, mixed conifer-broadleaf forest, and conifer forest were all recognized as suitable habitat.

Habitat is a key factor for pandas to survive and panda corridor zone is also vital. In recent years, panda traces (including footprints, dungs, etc.) in GNR (Figure 7) mainly concentrate in two parts, one at Liangfengya area and the other at Xigou valley. Some signs of panda activities occur beside the 108 National Road. This might be the results of the construction of the Qinling tunnel of 108 National Road and the protective measures of GNR. Actually, the forest structure has been recovering and the habitat structure has also been restored to connect the two local populations of pandas as a role of gene flow. Moreover, we can see a trend of migration to connect these single parts. This migration corridor is very important for pandas so that more effective measures should be taken to protect it and ensure it can be of most use. Nevertheless, we know that the road to Liangfengya has produced the pressure of traveling on panda migration habitat. The road impact might decrease the efficiency of the corridor. Also, the residences can cause much influence on the migration of pandas, especially the Donghe village located on this corridor.

In addition, human daily activities should not be ignored. Therefore, as for GNR, the best way to protect the pandas might be shifting the villagers out by the way of negotiation. In this way, the area suitable for giant pandas' survival could be enlarged, which would be a major factor to increase the local population of giant pandas.

As one of the major distribution area of giant pandas in GNR, Xigou valley has the characteristics for giant panda survival as pointed out by Liu et al. (2008), including moderate elevation, moderate slope, mixed conifer-broadleaf forest structure and suitable bamboo quality. All these factors contribute to a suitable habitat for giant pandas to survive in Xigou valley. If Bashania fargesii bamboo could be planted deliberately where they previously had been growing, then the area might be used as winter habitat for giant pandas and through this the giant pandas' migration from FNR to GNR would be promoted (Liu et al., 2009).

\section{Conclusions}

At the end we concluded that (1) when not considering human activities, the "most suitable" potential habitat covers 6.03 ha occupying $0.04 \%$ of the total area with the main reason being very scarce distribution of Bashania fargesii bamboo. The unsuitable potential habitat covers $7.63 \%$ of the total area, where there is a very low coverage of bamboo distribution. The areas ranked "suitable" and "marginally suitable" are 12767.94 ha and 506.70 ha, representing 88.81 and $3.52 \%$ of the whole reserve respectively. (2) Under the impacts of residences and roads, the proportion of unsuitable area increases to $16.81 \%$. Compared with the potential habitat without consideration of impact of human activities, the percentage of unsuitable area increases by $9.18 \%$. The percentage of ranked "suitable" decreases from 88.81 to $61.89 \%$ of the total area while the proportion of ranked "marginally suitable" increases from $3.52 \%$ to $21.26 \%$. In the future, one way of protecting the habitat and the giant panda population is to reduce human activities as much as possible. The other way is to implement proper scientific management and effective measures to promote regeneration and restoration of the habitat that has been impacted or destroyed.

Acknowledgments. We gratefully acknowledge financial support from International Cooperation Programme:Monitoring the restoration of giant panda habitat in the Qinling Mountains (WH0633) sponsored by the State Forest Administration (SFA) of China.

\section{References}

Chen, G.S., Qi, D.H., Yang, Y.B., Hu, J.Y., and Yang, L. (2005). Plant community structural characteristics of giant panda habitat in Xiaozhaizigou Nature Reserve, Sichuan, Guihaia, 25(4), 305-309. http://dx.doi.org/10.3969/j.issn.1000-3142.2005.04.004

Liu, X.H., Bronsveld, M.C., Toxopeus, A.G., and Kreijns, M.S. (1997). GIS application in research of wildlife habitat change - a case study of the giant panda in Wolong Nature Reserve, J. Chin. Geogr., 7(4), 51-60.

Liu, X.H., Bronsveld, M.C., Toxopeus, A.G., Kreijns, M.S., Zhang, H.M., Tan, Y.C., Tang, C.X., Yang, J., and Liu, M.C. (1998). Application of digital terrain model (DTM) in the habitat research of endangered animal species, Prog. Geogr., 17(2), 50-58.

Liu, X.H. (2001). Mapping and modelling the habitat of giant pandas in Foping Nature Reserve, China. Febodruk Besloten Vennoo- 
tschap (BV), Enschede, The Netherlands.

Liu, X.H, Bronsveld, M.C., Skidmore, A.K., Want, T.J., Dang, G.D., and Yong, Y.G. (2004). Mapping habitat suitability for giant pandas in Foping nature Reserve, China. In: Lindburg D, Baragona K. eds. Giant pandas: Biology and Conservation, London. University of California Press, 176-186.

Liu, X.H., Toxopeus, A.G., Skidmore, A.K., and Shao, X.M. (2005). Giant panda habitat selection in Foping Nature Reserve, China, $J$. wildl. manage., 69(4), 1623-1632. http://dx.doi.org/10.2193/0022541X (2005)69[1623:GPHSIF]2.0.CO;2

Liu, X.H., Skidmore, A.K., and Bronsveld, M.C. (2006). Assessment of giant panda habitat based on integration of expert system and neural network, Chin. J. Appl. Ecol., 17(3), 438-443.

Liu, X.H., and Jin, X.L. (2008). Habitat feature of giant pandas' high-frequency activity area on southern slope of the Qinling Mountains and habitat selection of giant panda, Chin. J. Ecol., 27 (12), 2123-2128.

Liu, X.H., Shao, X.M., He, X.B., Tian, R.X., Zhu, Y., and Dang, G.D. (2009). Giant panda habitat dynamics in a recovering nature reserve. In: proceeding of the 23rd annual meeting \& 2009 international congress for conservation biology, Beijing, China. 11-16 July 2009, P299-300

Liu, J.G., Ouyang, Z.Y., Taylor, W.W., Groop, R., Tan, Y.C., and Zhang, H.M. (1999). A framework for evaluating the effects of human factors on wildlife habitat: the case of Giant Pandas, Conserv. Biol., 13(6), 1360-1370. http://dx.doi.org/10.1046/j.1523-1739.199 9.98418.x

OuYang, Z.Y., Liu, J.G., Xiao, H., Tan, Y.C., and Zhang, H.M. (2001).
An assessment of giant panda habitat in Wolong Nature Reserve, Acta Ecol. Sin., 21(11), 1869-1874.

Pan, W.S., Gao, Z.S., and Lü, Z. (1988). Natural refuge of the giant panda in Qinling Mountains. Peking University Press, Beijing.

Pan, W.S., Lü, Z., Zhu, X.J., Wang, D.J., Wang, H., Long, Y., Fu, D.L., and Zhou, X. (2001). A chance for lasting survival. Peking University Press, Beijing.

Ron, S., and Jyrki, K. (2001). Integrating spatial multi-criteria evaluation and expert knowledge for GIS-based suitability modeling, Landscape Urban Plann., 55(2), 79-93. http://dx.doi.org/10.1016/ S0169-2046(01)00120-7

Xiao, Y., OuYang, Z.Y., Zhu, C.Q., Zhao, J.Z., He, G.J., and Wang, X.K. (2004). An assessment of giant panda habitat in Minshan, Sichuan, China, Acta Ecol. Sin., 24(7), 1373-1379.

Xu, W.H., OuYang, Z.Y., Jiang, Z.Y., Zheng, H., and Liu, J.G. (2006). Assessment of giant panda habitat in the Daxiangling Mountain Range, Sichuan, China, Biodiv. Sci., 14(3), 223-231. http://dx.doi. org/10.1360/biodiv.050191

Yong, Y.G., Liu, X.H., Wang, T.J., Skidmore, A.K., and Prins, H.H. (2004). Giant panda migration and habitat utilization in Foping Nature Reserve, China. In: Lindburg D, Baragona K. eds. Giant pandas: Biology and Conservation, London. University of California Press, 159-169.

Zhang, S., Liu, X.H., Jin, Q., Li, J.H., Jin, X.L., and Wei, F.W. (2004). The relationship between landscape pattern and the habitat of giant pandas on the southern slope of the middle Qinling Mountains, Acta Ecol. Sin., 24(9), 1950-1957. 